\title{
Numerical simulation of shear-strengthening of reinforced concrete beams by CFRP under cyclic loading
}

\author{
Simulación numérica del refuerzo de corte de vigas de hormigón armado mediante CFRP bajo \\ carga cíclica
}

Shahriar Shahbazpanahi (Main and Corresponding Author)

Department of Civil Engineering, Sanandaj Branch, Islamic Azad University

Sanandaj, Kurdistan (Iran)

sh.shahbazpanahi@iausdj.ac.ir

Hunar Farid Hama Ali

Department of Building and Construction Engineering, University of Halabja

Kurdistan Region (Iraq)

hunar.hamaali@uoh.edu.iq

Manuscript Code: 1187

Date of Acceptance/Reception: 25.06.2019/02.10.2018

DOI: 10.7764/RDLC.18.2.271

\begin{abstract}
A novel finite element model is proposed to simulate reinforced concrete (RC) beams strengthened in shear by carbon fibre-reinforced polymer (CFRP) plate under cyclic loading. A spring element is developed to simulate the fracture zone based on the virtual crack in the sub-concrete material. The mass and damping matrix of the spring element is defined to model crack propagation in the sub-concrete material on nonlinear fracture mechanics under cyclic loading. A new energy release rates is computed to compare to the critical energy release rate of the sub-concrete material. A bar element is set parallel to the spring element to model the effect of the CFRP strengthened in shear and to calculate the energy dissipation rate by the CFRP based on virtual crack. The mass and damping matrix of the bar element is defined as well. When the finite element model is performed, the energy release rates can be computed simultaneously. Crack propagation can be studied with the implementation of new fracture criterion. The results of the proposed model are compared with the conventional fracture models carried out by commercial ABAQUS software based on linear elastic fracture mechanics and the previous experimental tests data. The results from the proposed model are in reasonable agreement with the results of previous experimental test.
\end{abstract}

Keywords: Fracture, beams, cyclic loading, CFRP, reinforced concrete, shear-strengthening.

Resumen

Se propone un nuevo modelo de elementos finitos para simular vigas de hormigón armado (RC) reforzadas en corte por placa de polímero reforzado con fibra de carbono (CFRP) bajo carga cíclica. Se desarrolla un elemento de resorte para simular la zona de fractura en función de la grieta virtual en el material sub-concreto. La matriz de masa y amortiguación del elemento de resorte se define para modelar la propagación de grietas en el material sub-concreto en la mecánica de fractura no lineal bajo carga cíclica. Se calcula una nueva tasa de liberación de energía para compararla con la tasa crítica de liberación de energía del material sub-concreto. Se establece un elemento de barra paralelo al elemento de resorte para modelar el efecto del CFRP reforzado en el corte y para calcular la tasa de disipación de energía por el CFRP en base a la grieta virtual. La matriz de masa y amortiguación del elemento de barra también se define. Cuando se realiza el modelo de elementos finitos, las tasas de liberación de energía se pueden calcular simultáneamente. La propagación de grietas puede estudiarse con la implementación de un nuevo criterio de fractura. Los resultados del modelo propuesto se comparan con los modelos de fractura convencionales realizados por el software comercial ABAQUS, basado en la mecánica de fractura lineal elástica y los datos de pruebas experimentales anteriores. Los resultados del modelo propuesto están razonablemente de acuerdo con los resultados de la prueba experimental previa.

Palabras clave: Fractura, viga, carga cíclica, CFRP, hormigón armado, reforzamiento en el corte.

Introduction

Fiber reinforced polymer (FRP) composites have been increasingly used in concrete structures in recent years because of their corrosion resistance, low weight, high tensile strength and large strain (Rahman, Jumat, Hosen, \& Islam, 2016). Shear strengthening of beams can be implemented quickly by external carbon fibre-reinforced polymer (CFRP). Accurate prediction of crack propagation in composite material is important to improve structural reliability, integrity, durability, and serviceability (Anyfantis \& Berggreen, 2014; Beaumont \& Soutis, 2016). Furthermore, the effect strengthened in shear by CFRP on crack propagation in the sub-concrete material (Figure 1) is essential (Selman \& Alver, 2015; Bruno, Greco, \& Feudo, 2017).

Over the last decade, many studies have focused on the debonding of CFRP plate (Harries, Eveslage , Aidoo, \& Bro , 2010; Achintha \& Burgoyne, 2011; Chen, Chen, \& Teng, 2012; Hadjazi, Sereir, \& Amziane, 2012; Harries, Hamilton, Kasan 
, \& Tatar, 2012; Bruno, Greco, \& Lonetti, , 2013; Diab \& Farghal, 2014; Palmieri \& Lorenzis, 2014). However, to the author's best knowledge, crack propagation model of concrete beams shear -strengthened with CFRP subjected to cyclic loading is not available in the literature.

Hillerborg et al. (1976) were the first to use the cohesive model to assess crack propagation in concrete structures (Brake \& Chatti, 2013). A fracture zone was found in front of the crack. This zone is known as the fracture process zone (FPZ). The FPZ is able to transfer normal and shear stress (Shahbazpanahi, 2017). One of the most conventional interface elements to simulate the FPZ is the discrete cohesive element (Xie \& Biggers, 2006). In this element, the cohesive zone behaves as a spring. Thus, a spring element is set between interfacial node pairs along the crack line. One of the techniques to evaluate crack propagation is the virtual crack technique. This technique is conventional, popular and provides acceptable results.

Figure 1. The FPZ in sub-concrete and shear-strengthened by CFRP. (Source: Authors).

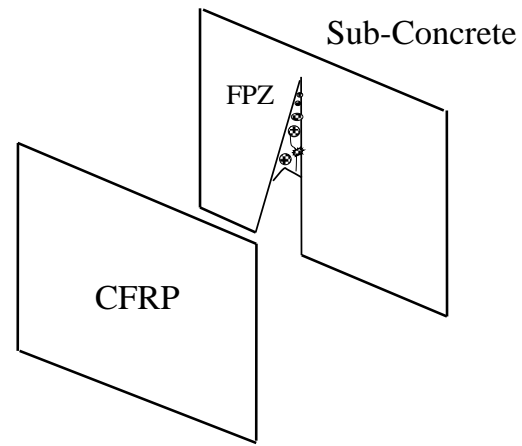

An accurate estimation of the energy release rate is essential to predict the crack propagation in shear-strengthening of reinforced concrete beams (Zheng. , Dai, \& Fan, 2015). In the fracture mechanics theory, the energy release rate is calculated to predict the crack propagation. In the finite element model, the energy release rate depends on the element stiffness. Therefore, in the finite element model, it is important to calculate and formulate accurate element stiffness, mass and damping matrix to predict the influence of the shear-CFRP on the propagation of the crack subjected to cyclic loading.

This research focuses on modeling of the beams strengthened in shear by CFRP and crack propagation criterion. A spring element is proposed to simulate the fracture zone based on the virtual crack in the sub-concrete material. A bar element is placed parallel to the spring element to predict crack propagation of the beams strengthened in shear by CFRP. Then, the mass and damping matrix of these elements are defined to model the crack propagation under cyclic loading. A new energy release rate is computed based on these two stiffness matrices to predict the crack propagation. In the present study, crack propagation in the concrete is of more interest than the slip between concrete and CFRP elements.

Methods and materials

\section{Interfaces element for virtual crack}

Figure 2 illustrates a spring element to model the discrete cohesive element in the concrete and bar element for simulating the effect of the CFRP on crack parallel with the first one bar at the crack tip between the two nodes. These elements are set to calculate the internal forces due to cohesive zone and the CFRP. The spring and bar elements are set at the crack tip between node numbers ' 1 ' and ' 2 '. The shear stiffness in the CFRP is zero, therefore, stiffness matrix in the local coordinate system is as follows:

$$
\mathbf{K}=\left[\begin{array}{cc}
k_{x} & 0 \\
0 & k_{y}
\end{array}\right]+E_{F} A_{F} / w_{c}\left[\begin{array}{cc}
1 & -1 \\
-1 & 1
\end{array}\right]
$$

where $k_{x}$ and $k_{y}$ are the shear and normal stiffness of the cohesive zone. The $w_{c}, A_{F}$ and $E_{F}$ are the critical crack opening, CFRP area section and the elastic modulus of the CFRP, respectively. The initial CFRP length, truss element, is assumed equal to $w_{c}$. 


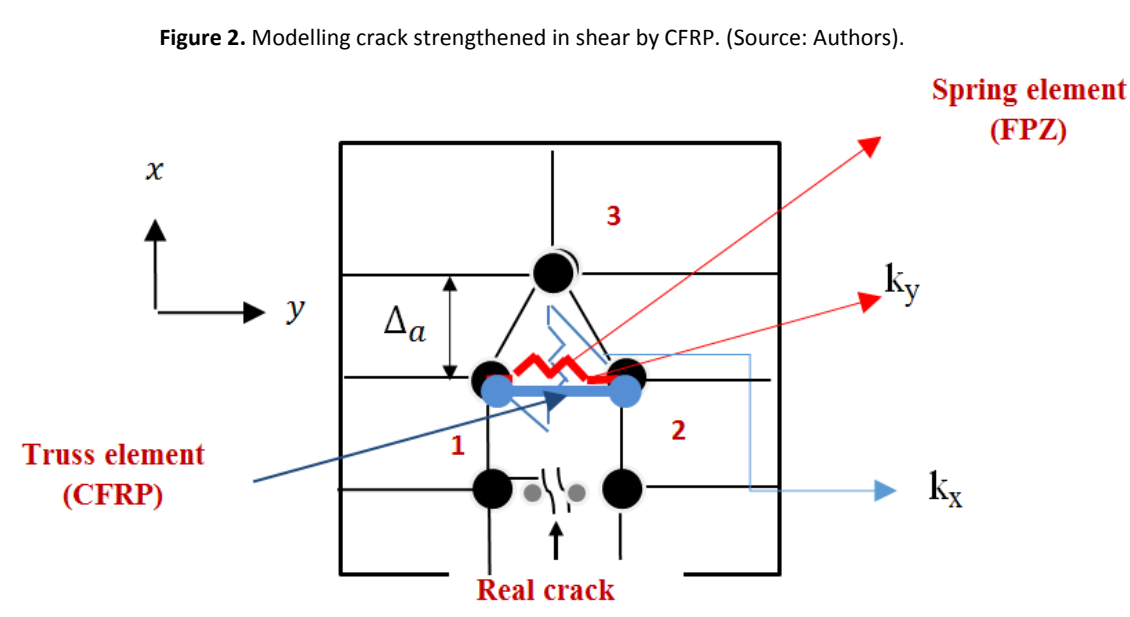

The shear and normal stiffness of the cohesive zone in the elastic region can be calculated as:

$\mathrm{k}_{\mathrm{x}}=\frac{\mathrm{GB} \Delta_{\mathrm{a}}}{\mathrm{h}}$ and $\mathrm{k}_{\mathrm{y}}=\frac{\mathrm{EB} \Delta_{\mathrm{a}}}{\mathrm{h}}$

where $\mathrm{B}, \mathrm{h}$ and $\Delta_{\mathrm{a}}$ are the beam thickness, the FPZ thickness and the element size, respectively. The $\mathrm{E}$ is Young's modulus and $\mathrm{G}$ is shear modulus of the concrete.

\section{Mass and damping matrix of the interfaces element in the sub- concrete}

Cracks require special modelling if subjected to repeated loading. A dynamic problem has to be solved if nonlinear fracture mechanics models are used. An improved damping matrix is used in such a way that it can model the propagation of a crack based on an accurate stiffness matrix. This model improves the analysis of crack propagation subjected to dynamic loading and is more accurate than other existing models. In this study, the mass matrix, $\mathbf{M}_{\mathbf{1}}$, of the interface element to model crack propagation in concrete is given by:

$\mathbf{M}_{1}=\frac{\rho_{1} w_{c}}{2}\left[\begin{array}{ll}1 & 0 \\ 0 & 1\end{array}\right]$

where $\rho_{1}$ is mass density of concrete. Rayleigh damping matrix in concrete, $\mathbf{C}_{1}$, known as a linear combination of the mass and stiffness matrices, is:

$\mathbf{C}_{1}=\alpha_{1} \mathbf{M}_{\mathbf{1}}+\boldsymbol{B}_{1} \mathbf{K}$

where $\alpha_{1}$ and $B_{1}$ are the damping coefficients.

\section{Mass and damping matrix of the interfaces element}

A bar element is proposed to simulate the effect of the CFRP on the crack. In this study, the mass matrix, $\mathbf{M}_{\mathbf{2}}$, of the element of side face strengthened members by CFRP is given by:

$\mathbf{M}_{\mathbf{2}}=\frac{\rho L_{F}^{2} t_{F}}{2}\left[\begin{array}{ll}1 & 0 \\ 0 & 1\end{array}\right]$

where $t_{F}$ and $L_{F}$ are thickness and width of the CFRP element, respectively. Rayleigh damping matrix, $\mathrm{C}_{2}$, known as a linear combination of the mass and stiffness matrices, is,

$\mathbf{C}_{2}=\alpha_{2} \mathbf{M}+\beta_{2} \mathbf{K}$

where $\alpha_{2}$ and $B_{2}$ are the damping coefficients. These mass and damping coefficients are calculated from modal analysis with initial stiffness by program automatically. Thus, the local coordinate system, mass and damping matrix are defined by $\mathbf{M}=\mathrm{M}_{1}+\mathrm{M}_{2}$ and $\mathrm{C}=\mathrm{C}_{1}+\mathrm{C}_{2}$. 


\section{Crack propagation criterion}

Figure 3 shows the softening behavior of sub-concrete martial. In the present research, a triangular curve is used to model behavior of cohesive zone. The value of stiffness, $k_{l}$, is determined as:

$k_{l}=\frac{\sigma_{l}}{w_{l}}$

where $\sigma_{l}$ and $w_{l}$ are the stress and opening in the softening part, respectively. On other hand:

$\frac{f_{t}}{w_{c}}=\frac{\sigma_{l}}{w_{c}-w_{l}} \Rightarrow \sigma_{l}=\frac{f_{t}\left(w_{c}-w_{l}\right)}{w_{c}}$

where $w_{c}$ is the maximum opening and $f_{t}$ is tensile strength of the concrete. Substituting Eq.(8) for Eq. (7) leads to:

$k_{l}=\frac{f_{t}\left(w_{c}-w\right)}{w_{l} w_{c}}$

During the cyclic load, the stiffness of concrete is degraded. In the present study, to determine effective stiffness of concrete under cyclic loading, the stiffness of concrete is proposed as:

$k_{N}=\left(1-0.33 \frac{N}{N_{f}}\right) k_{l}$

where $k_{N}$ is the effective stiffness of concrete at $N$ cycles. The $N_{f}$ is the number of loading cycles to failure (Li, Huang, Guo, Zheng, Lin, \& Chen, 2017).

On other hand, the energy release rate of Mode I, $G_{1}$, from Figure 3 will be:

$\mathrm{G}_{1}=\frac{w_{l}}{2}\left(f_{t}+\sigma_{l}\right)$

Substituting Eq. (9) for Eq. (11) leads to:

$\mathrm{G}_{l}=\frac{w_{l}}{2}\left(f_{t}+\frac{f_{t}\left(w_{c}-w\right)}{w_{l} w_{c}}\right)=\frac{f_{t}\left[w_{l} w_{c}-w_{l}\left(w_{c}-w\right)\right]}{2 w_{c}}$

For the CFRP on crack propagation to have an effect on the side face energy dissipation rate, a criterion is required. In the present study, the energy dissipation rate by the CFRP, $G_{F R P}$, based on virtual crack is proposed as follows (Xie \& Waas, 2006 ):

$\mathrm{G}_{\mathrm{FRP}}=\frac{\left(E_{F}+k_{N}\right)\left(u_{2}-u_{4}\right)^{2}}{2 t_{F} \Delta_{\mathrm{a}}}$

where $u_{2}$ and $u_{4}$ are the displacement components of node " 1 " and node " 2 " in the y directions, respectively.

In the plane concrete element (without CFRP), when $w_{l}<w_{c}, k_{y}=k_{N}$ is determined from Eq. (10) and the $\mathrm{G}_{1}$ is determined from Eq. (12). When $w_{l}>w_{C}, k_{y}$ is equal to zero, $\mathrm{G}_{1}=\mathrm{G}_{\mathrm{IC}}$ and the element is removed. In both cases, the second part of Eq. (1) is set to zero. The $G_{I C}$ is the critical fracture energy of Mode $I$ in the concrete. For side face strengthened elements, when $\left(u_{2}-u_{4}\right)<w_{c}$, the energy release rate is $\left(\mathrm{G}_{1}-\mathrm{G}_{\mathrm{FRP}}\right)$. Therefore, the crack will propagate if $\left(\mathrm{G}_{1}-\mathrm{G}_{\mathrm{FRP}}\right)>\mathrm{G}_{\mathrm{IC}}$. When $\left(u_{2}-u_{4}\right)>w_{c}$ stiffness matrix, Eq. (1), is equal to zero, the interface elements, the bar and truss elements, are removed. 


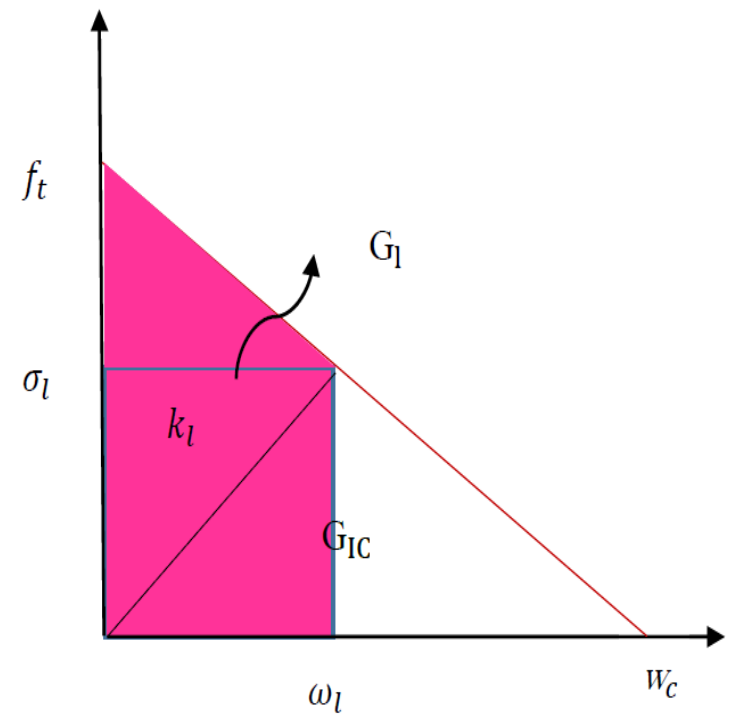

A two-dimensional plane stress finite element method is used to analyze shear-strengthening of reinforced concrete beams by CFRP under cyclic loading. The behaviour of the CFRP is elastic but elastic-perfect plastic behaviour is considered to model the behaviour of the steel bars. Four-node isoparametric elements are used for concrete isotropic behaviour. The bar elements are employed to simulate the soffit CFRP in U-wrap, longitudinal steel, and stirrup. In the present study, the stress-slip between CFRP and concrete are modelled using the approach introduced by Nakaba et al. (2001). A four -node interface element for transferring shear in nodal forces is used between the four-node isoparametric quadrilateral element concrete and CFRP element. The FEAPpv program code on nonlinear fracture mechanics is developed to analyse shear strengthening beams by CFRP under cyclic loading. The springs and bars are implemented as interfaces elements in the User Subroutine FEAPpv. To solve the non-linear problem, dynamic relaxation method is used.

Moreover, to validate the proposed model, the three dimension (3D) finite element model of beams by ABAQUS software was employed. Software such as the ABAQUS applies the linear fracture mechanics to model the crack propagation. The proposed model can be compared to the conventional CZM approach as used in analysis software such as FEA software, ABAQUS. The beam was modeled by ABAQUS software with 3469 C3DBR elements. The FRPs are modeled by using the $S 4$ shell in ABAQUS software.

Results and discussion

\section{Validation of crack propagation in plain concrete beam}

To validate the proposed numerical method under cyclic loading, a three point bending, single edge notch concrete beam was modeled as shown in Figure 5 . This beam was tested by Brake and Chatti (2013). The beam had a span of 400 $\mathrm{mm}$, a depth of $100 \mathrm{~mm}$, and a width of $100 \mathrm{~mm}$. The length of initial notch was $15 \mathrm{~mm}$. During the loading phase, a crack opening at a controlled loading rate of $0.0005 \mathrm{~mm} / \mathrm{s}$ was used. During the unloading phase ( $25 \mathrm{~N} / \mathrm{s})$, force control was used. Young's modulus, Poisson's ratio and tensile strength of concrete were assumed to be 24,800, 0.18 and 2.89 $\mathrm{MPa}$ respectively. The parameter values of fracture were $G_{c}=150 \mathrm{~N} / \mathrm{m}, w_{c}=0.12 \mathrm{~mm}$ and $w_{0}=0.001 \mathrm{~mm}$.

Figure 5. A plain concrete beam with three point bending (Unit: $\mathrm{mm}$ ). (Source: Authors).

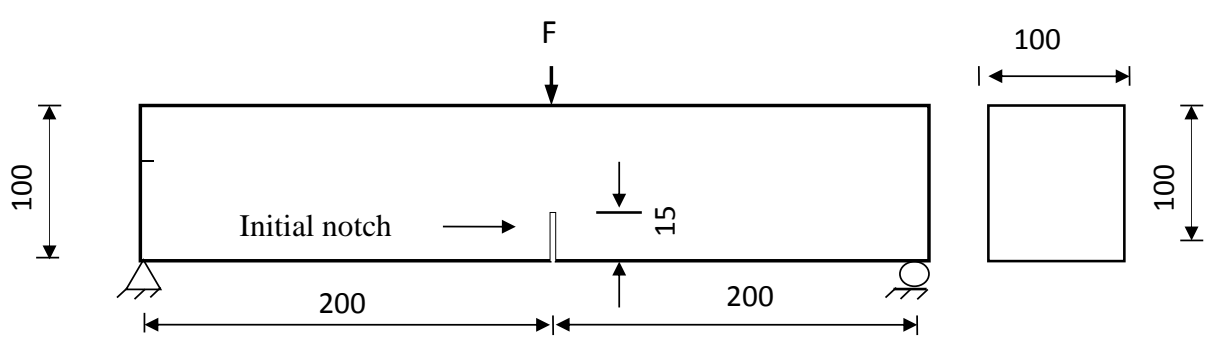


Figure 6 depicts the FPZ length, the stress-free region length, and the crack opening mouth displacement (COMD) at the pick load by the proposed model. The COMD was $0.0524 \mathrm{~mm}$ while the deflection at the mid-span was $0.341 \mathrm{~mm}$. The FPZ propagation reached almost three-fourth of the beam depth after the thirteenth step of loading. At the tenth step of loading, the FPZ was fully propagated and the stress-free region length appeared.

Figure 6. Final crack predict by the proposed model (Unit: $\mathrm{mm})$. (Source: Authors)

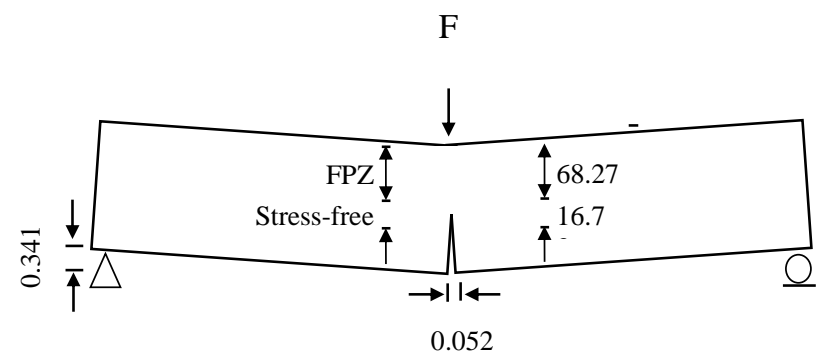

Figure 7 shows the crack paths predicted by ABAQUS software at the pick load. The FPZ length was $67.11 \mathrm{~mm}$. The FPZ propagation elements are shown in red colors, while the stress-free elements are displayed in black. It should be noted that the crack path is smooth. The tensile damage is defined from 0 to 1 in the ABAQUS software. The results demonstrated that the maximum value of the damage parameter is $0.99>0.1$. Therefore, the tensile damage occurred near the notch and along the red lines as shown in Figure 7.

Figure 7. Finite element mesh and crack path by ABAQUS software. (Source: Authors).

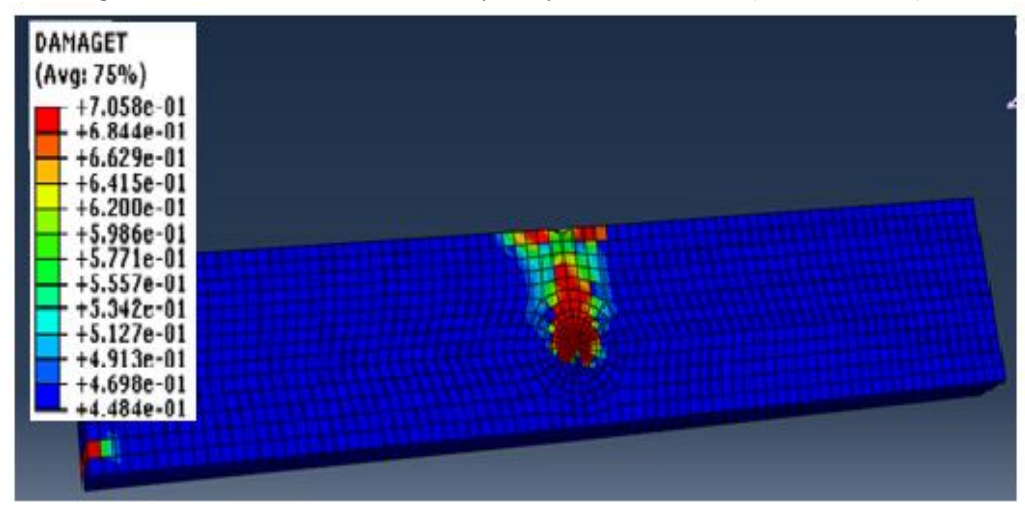

Figure 8 illustrates the result of the load versus crack mouth sliding displacement (CMSD) curve for the beam from the experiment by Brake and Chatti [17], the proposed model and the ABAQUS software. The proposed model showed excellent accuracy compared to the experiment by Brake and Chatti (2013) for displacement (4.3-9.8\% difference). In the ABAQUS software model, the relative error for displacement is $16.4-23 \%$ difference compared to the experiment by Brake and Chatti (2013). The proposed model demonstrated well the observed initial stiffness, maximum strength and softening stiffness.

Figure 8. Load Versus CMSD obtained by (a) Experiment test by Brake and Chatti (2013) and the proposed model results and (b) ABAQUS software data. (Source: Authors)

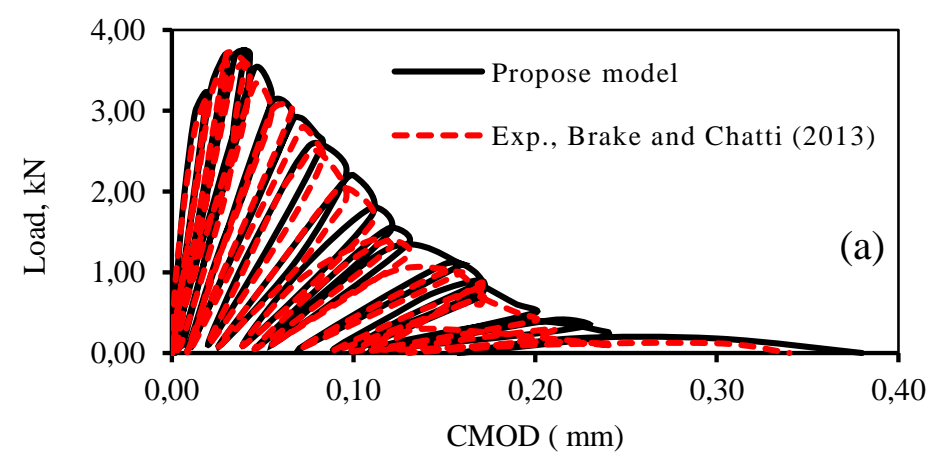




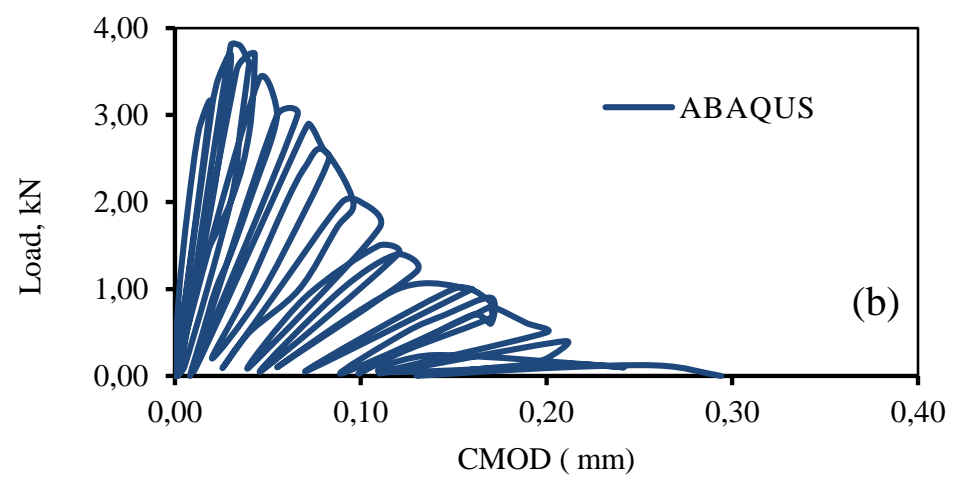

\section{Validation of crack propagation concrete beam strengthened by CFRP}

To validate the proposed numerical model in concrete beam strengthened by CFRP, the experimental data reported by Lin et al. (2014) was chosen. The test arrangement, the boundary conditions and the geometry of the RC beam are illustrated in Figure 9. The beams (V. series) were designed based on shear failure.

The compressive strength, tensile strength and fracture energy were $21.2 \mathrm{MPa}, 2.1 \mathrm{MPa}, 100 \mathrm{~N} / \mathrm{m}$ respectively. The Steel tensile yielding strength was $402.6 \mathrm{MPa}$. Sheet thickness and tensile modulus of CFRP are $0.138 \mathrm{~mm}$ and $235 \times 10^{3}$ $\mathrm{MPa}$, respectively. The range of cyclic load is $16.16 \mathrm{kN}-4.46 \mathrm{kN}$ with 2.50 loading amplitude.

Figure 9. Three-point bending CFRP reinforced concrete beam. (Source: Authors).

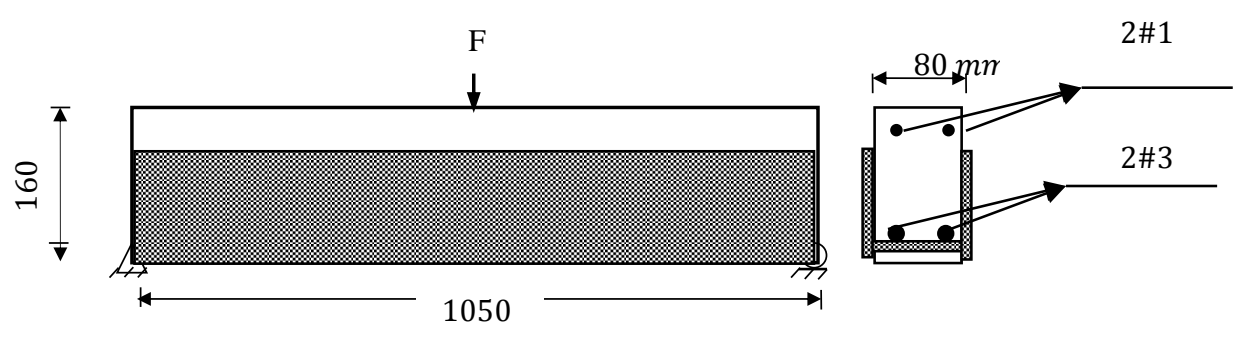

The data from the proposed model is compared with experimental records by Lin et al. (2014) and the numerical model by ABAQUS software in Figure 10. The numerical results of the proposed model were in good agreement with the experimental data by Lin et al. (2014) (6-11\% difference). It can be observed that failure load in the proposed model is predicted within a 7.2-10.6\% margin of difference (compared to experimental data by Lin et al. (2014)). It can be seen that the curve in the present study is similar to the experimental data. However, The curve by the Abacus software was over (higher than) the predicted results. ABAQUS software data showed a greater margin of difference (19.6- 28\%) compared to the experimental data by Lin et al. (2014). In the proposed model, the beam failed by shear failure at cycle 1845. In the test by Lin et al. (2014), the beam failed by shear failure at cycle 2005. However, the beam failed by shear failure at cycle 3625 by the ABAQUS software. Thus, the present model improved the analysis of crack propagation under dynamic load.

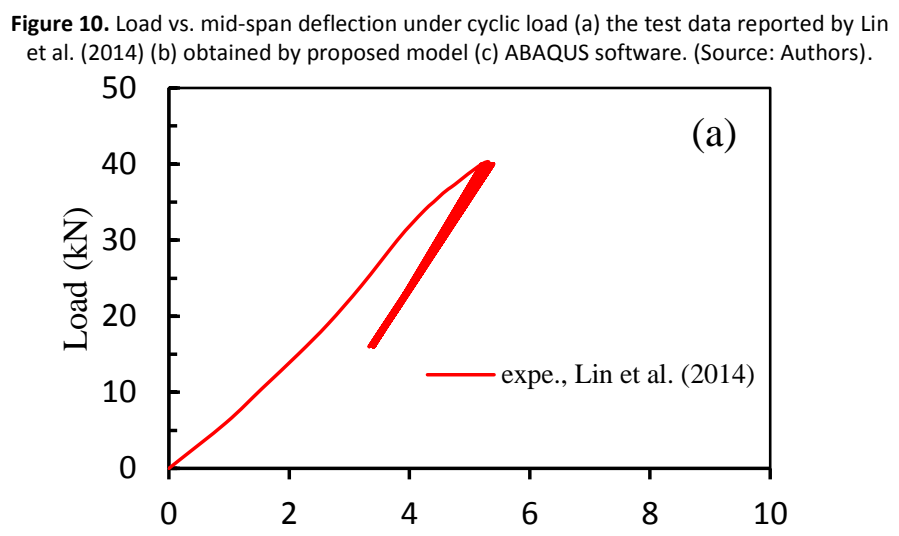

Mid-span deflection (mm) 

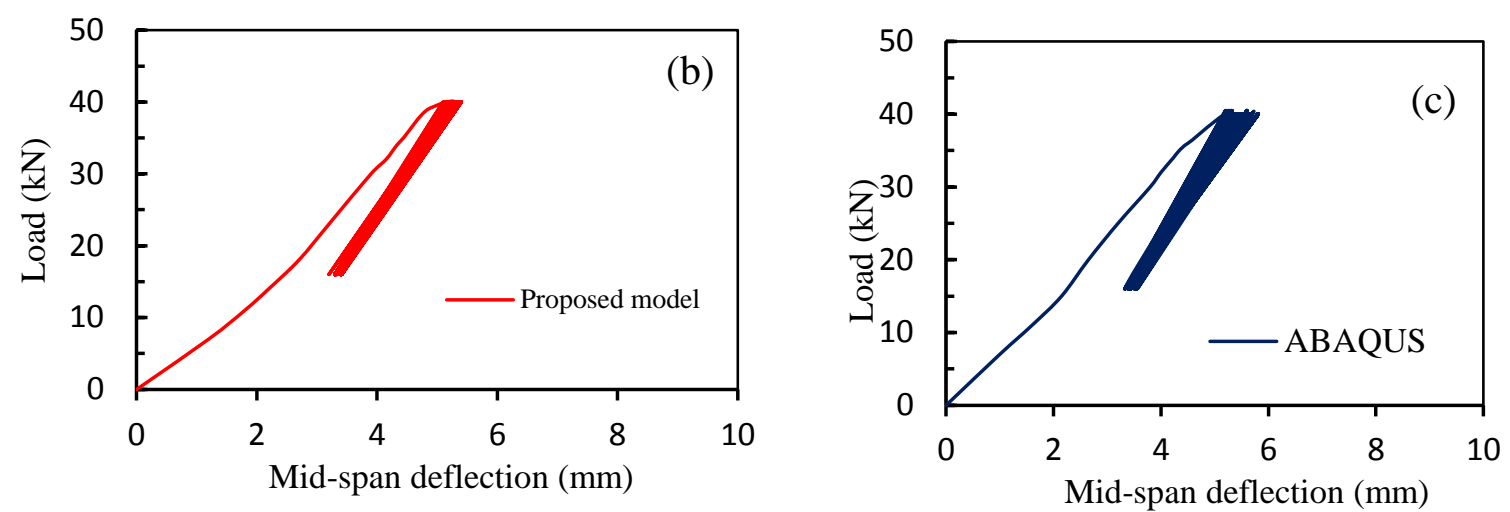

Figure 11 shows the crack paths obtained by the proposed model. The shear crack is diagonal on the support in U-wrap beam. The failure in the beam with the CFRP sheet occurred at $38.91 \mathrm{kN}$, while it was reported to be $39 \mathrm{kN}$ in the test results. According to the results obtained by the proposed model, the FPZ length increased under dynamic load when CFRP sheets were used. Figure 11(a) illustrates three flexural cracks initiated and propagated toward the loading point and also three flexural-shear cracks. The shear cracks stopped initiating and propagating in the shear span because of the shear strengthening by CFRP. The flexural crack began to appear at a load of approximately $35 \mathrm{kN}$. The flexuralshear cracks propagated from the mid-depth of the beam toward the point of the applied load. Figure 11(a) shows that two shear cracks were observed in the vicinity of the support. However, in the control beam [Figure 11(b)], three shear cracks were observed. The main shear crack of the control beam in the support [Figure 11(b)] is longer than the beam strengthened by CFRP [Figure 11(a)]. A comparison of the shear cracks in the beam by CFRP [see Figure 11(a)] and the control beam [see Figure 11(a)] shows the use of CFRP sheets arrests the propagation of shear crack.

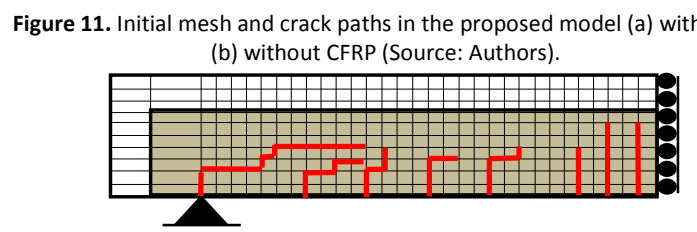

(a)

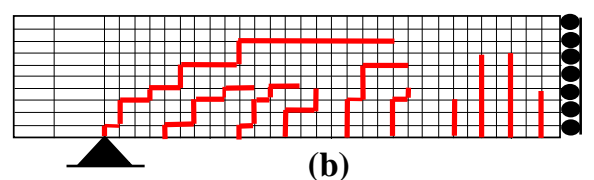

Figures 12 (a) and 12 (b) illustrate the cracking process of the U-wrap and the control beam predicted by ABAQUS software. It can be seen that six flexural cracks occur at mid-span (Figure 12(b)) in the control beam. However, there are four flexural cracks in the shear-strengthened beam. The number of flexural-shear cracks is 2 in the control beam compared to no main flexural-shear cracks predicated in the beam strengthened by CFRP. The findings of the ABAQUS software showed the main diagonal crack formed at the support in the control beam but appeared through the shear span in the shear-strengthened beam.

Figures 11 and 12 show that the predicted cracking process in the present study in general agreed with that of the ABAQUS software. It is noteworthy that the shear crack near the support could not be modeled well by the ABAQUS software because in the ABAQUS software only cracks on the tensile face of the beam are allowed to initiate.

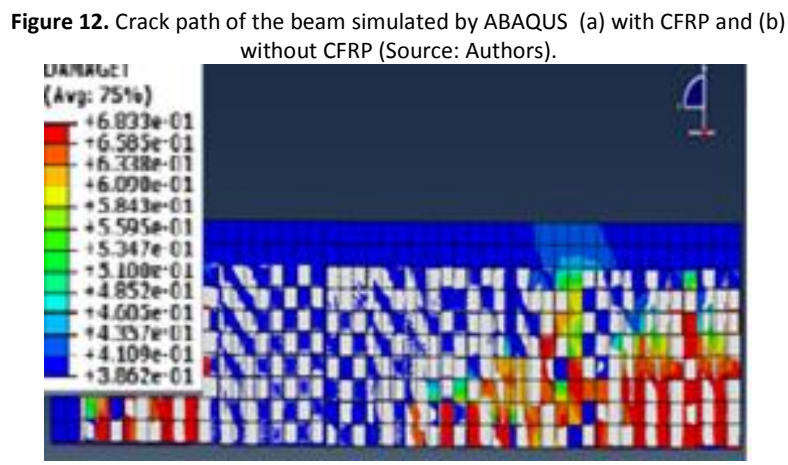

(a) 


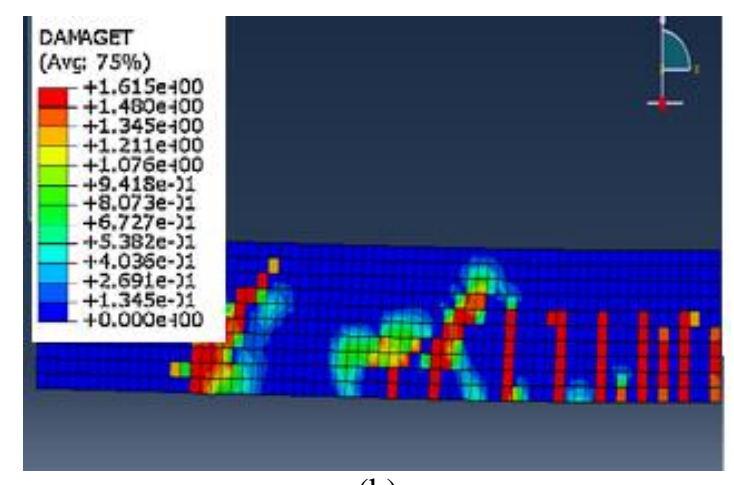

(b)

Figure 13 shows load - the mid-span deflection with deferent mesh to study mesh-size sensitivity of proposed model and ABAQUS software. Mesh (a) of the proposed model had 878 elements [element average size was $16 \mathrm{~mm} \times 14 \mathrm{~mm}$ ]. Mesh (b) of the proposed model had 1,568 elements [element average size was $12 \mathrm{~mm} \times 10 \mathrm{~mm}$ ]. Mesh (c) of the proposed model had 2,066 elements [element average size was $10 \mathrm{~mm} \times 10 \mathrm{~mm}$ ]. The approximate matching of the three curves demonstrates independence from mesh size (Figure 13(a)). Mesh (a) modeled by ABAQUS software had 2,254 elements [element average size was $10 \mathrm{~mm} \times 8 \mathrm{~mm}$, with finer mesh $(6 \mathrm{~mm} \times 4 \mathrm{~mm})$ ]. Mesh (b) modeled by ABAQUS software had 2,784 elements [element average size was $8 \mathrm{~mm} \times 6 \mathrm{~mm}$, with finer mesh $(6 \mathrm{~mm} \times 6 \mathrm{~mm})$ ]. Mesh (c) modeled by ABAQUS software had 3,032 elements [element average size was $6 \mathrm{~mm} \times 4 \mathrm{~mm}$, with finer mesh (4 mm $\times 2 \mathrm{~mm}$ )]. From Figure 13(b), it can be demonstrated that the accuracy modeling by ABAQUS software is independent from the element size.

Figure 13. Comparisons between Three Meshes of (a) proposed model and (b) ABAQUS model (Source: Authors).

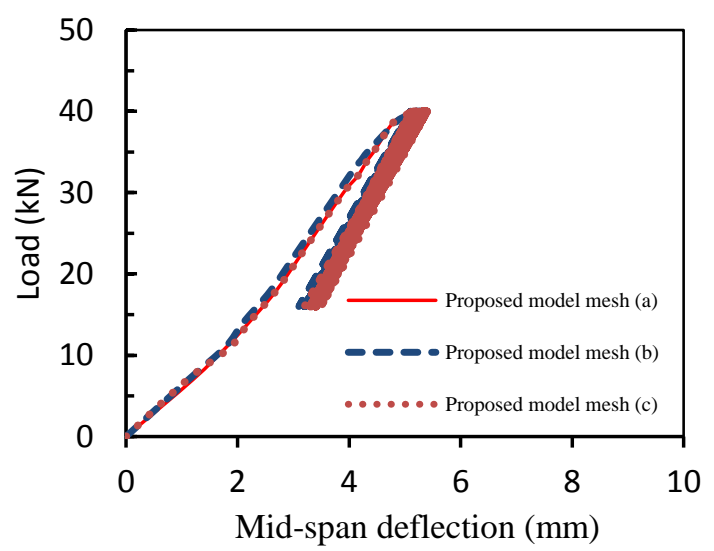

(a)

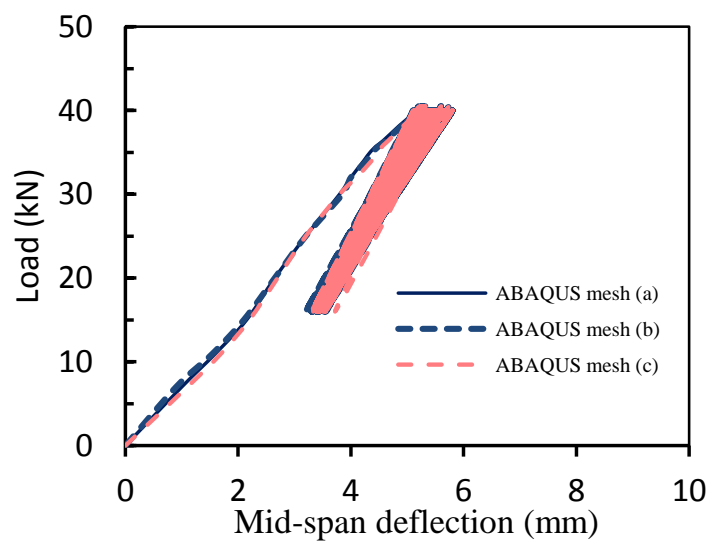

(b) 
The aim of this research was to provide the tools for developing the best and most accurate crack propagation model for the beams strengthened in shear by CFRP under cyclic load. An accurate spring element was applied to derive forces in nodes. A linear elastic bar element was used parallel to the spring element to model strengthened shear and to calculate the energy dissipation rate by the CFRP based on virtual crack. The mass and damping matrix of the bar and spring elements were defined to model crack propagation under cyclic loading. A crack propagation criterion was obtained from the strain energy release rate based on the stiffness. The model was accurate, efficient, and capable of modeling crack growth under cyclic loading. The model provides an accurate comparison of previous experimental test results. The results obtained by the proposed model showed that the length of the main shear crack was controlled by CFRP sheets before the compression zone in the beam. The numerical results of the proposed model were in good agreement with the experimental data (6-11\% difference). However the curve by the ABAQUS software over-predicted the results. The ABAQUS software data showed a greater margin of difference (19.6-28\%) compared to the experimental data.

\section{References}

Achintha, M., \& Burgoyne, C. (2011). Fracture mechanics of plate debonding: Validation against experiment. Construction and Building Materials, 25(6), 2961-2971.

Anyfantis, K., \& Berggreen, C. (2014). Characterizing and modeling brittle bi-material interfaces subjected to shear. Applied Composite Materials, 21(6), 905-919.

Beaumont, P., \& Soutis, C. (2016). Structural integrity of engineering composite materials: a cracking good yarn. Philosophical Transactions of the Royal Society A, 374(2071), 1-7.

Brake, N. A., \& Chatti, K. (2013). Prediction of size effect and non-linear crack growth in plain concrete under fatigue loading. Engineering Fracture Mechanics, 109, 169-185.

Bruno, D., Greco, F., \& Feudo, S. (2017). Edge debonding prediction in beams strengthened by FRP composite plates. Models, Simulation, and Experimental Issues in Structural Mechanics, 8, 105-124.

Bruno, D., Greco, F., \& Lonetti, , P. (2013). fracture-ALE formulation to predict dynamic debonding in FRP strengthened concrete beams. Composites Part B Engineering, 46, 46-60.

Chen, G., Chen, J., \& Teng, J. (2012). On the finite element modelling of RC beams shear-strengthened with FRP. Construction and Building Materials, 13-26.

Diab, H. M., \& Farghal, O. A. (2014). Bond strength and effective bond length of FRP sheets/plates bonded to concrete considering the type of adhesive layer. Composites: Part B, 58, 618-624.

Hadjazi, K., Sereir, Z., \& Amziane, S. (2012). Cohesive zone model for the prediction of interfacial shear stresses in a composite-plate RC beam with an intermediate flexural crack. Composite Structures, 94, 3574-3582.

Harries, K., Eveslage , T., Aidoo , J., \& Bro , W. (2010). Towards a standard test method for assessing FRP to concrete bond characteristics. The 5th international conference on FRP composites in civil engineering, (pp. 27-29). Beijing.

Harries, K., Hamilton, H., Kasan , J., \& Tatar, J. (2012). Development of standard bond capacity test for FRP bonded to concrete. 6th international conference on Fiber Reinforced Polymer (FRP) Composites in Civil Engineering (CICE). Rome.

Hillerborg, A., Modeer, M., \& Petersson, P. E. (1976). Analysis of crack formation and crack growth in concrete by means of mechanics and finite element. Cement and Concrete Research, 6, 773-782.

Li, D., Huang, P., Guo, X., Zheng, X., Lin, J., \& Chen, Z. (2017). Fatigue crack propagation behavior of RC beams strengthened with CFRP under cyclic bending loads. Fatigue Fracture Engineering Material Structure, 41, 212-222.

Lin, C. T., Wu, Y. H., \& Chin, W. (2014). Performance of CFRP-strengthened RC beams subjected to repeated loads. Journal of the Chinese Institute of Engineers, 37(8), 1007-1017.

Nakaba, K., Kanakubo, K., Furuta, T., \& Yoshizawa, K. (2001). Bond behavior between fiber reinforced polymer laminates and concrete. ACl Structural Journal, 98, 359-367.

Palmieri, V., \& Lorenzis, L. (2014). Multiscale modeling of concrete and of the FRP-concrete interface. Engineering Fracture Mechanics, 131, 150-175.

Rahman, M., Jumat, M., Hosen, M., \& Islam, A. (2016). Effect of adhesive replacement with cement mortar on NSM strengthened RC Beam. Revista de la Construcción , pp. 61-72.

Selman , E., \& Alver, N. (2015). A modified fiber-reinforced plastics concrete interface bond-slip law for shear-strengthened RC elements. Polymer Composites, DOI: 10.1002/pc.23535.

Shahbazpanahi, S. (2017). Mechanical analysis of a shear-cracked RC beam. Acta Scientiarum. Technology, 39(3), 285-290. 
Xie, D., \& Biggers, S. (2006). Progressive crack growth analysis using interface element based on the virtual crack closure technique. Finite Elements in Analysis and Design, 42(11), 977 - 984.

Xie, D., \& Waas, A. (2006). Discrete cohesive zone model for mixed-mode fracture using finite element analysis. Engineering Fracture Mechanics, 73(13), 1783-1796

Zheng, J., Dai, J., \& Fan, X. (2015). Fracture analysis of frp-plated notched concrete beams subjected to three-point bending. Journal of Engineering Mechanics, $142(3), 1-10$ 